\title{
Impact of Multilingualism and Multiculturalism on English Language Education: The Case of Arunachal Pradesh, India
}

\author{
Taw Azu \\ Research Scholar, Department of English \& Foreign Languages, \\ Tezpur University Assam India. \\ tawazu@gmail.com, 9436055601
}

\section{Doi:10.5901/mjss.2013.v4n11p665}

\begin{abstract}
Arunachal Pradesh is a multilingual and multicultural state with twenty five major tribes, sixty dialects and two languages i.e. Boti and Thai. The region was a terra-incognito until WW II and India's independence in 1947. Against this backdrop when schools were started in the late 1940s, the medium of instruction was Assamese in pre-primary and primary level. In the year 1974 the medium of instruction was switched to English at all level with Hindi (national language) as second language and Assamese/Sanskrit as third in middle level, in response to demands by the then NEFA students' union. English is the official language and the medium of instruction in the state since then. But despite 39 years of English teaching the standard of English is found deteriorating especially in Government schools. This paper will look into, and analyze the socio-cultural and linguistic impact of dominant languages, introduced in the multilingual and multicultural state like Arunachal Pradesh, India.
\end{abstract}

Keywords: multilingualism, multiculturalism, impact English, language, education.

\section{Introduction}

Multilingualism ${ }^{1}$ and multiculturalism ${ }^{2}$ is the hallmark of Indian national identity. India is home to five language families, namely, Indo-European, Dravidian, Austro-Asiatic, Tibeto-Burmese and Semito-Hamitic and many ethnic groups. According to 2001 census India has 22 Scheduled languages, 100 Non-Scheduled languages and 234 mother tongues (Census of India 2001, 2001). Diversity in language and ethnicity is not confined to a particular geographical location in India. It is a norm rather than an exception. "In fact, each part of India is a kind of replica of the bigger cultural space called India" (Shailendra Kumar Singh eds. 2009 P: xii). One of the most diverse region in the country is India's northeast, comprising of the seven states, viz. Assam, Arunachal Pradesh, Meghalaya, Mizoram, Nagaland, Tripura and Manipur. Lately Sikkim has also been added in the group. Each of these states has many groups of people speaking different languages and following a distinct cultural way of life. Discussing about the difficulty in classification of languages in the north east, particularly the Naga group, Thurgood and Lapolla says "lexical comparison, however, is peculiarly difficult for the two dozen or more 'Naga' languages, for they seem almost perversely diverse, as if the people had spent several centuries deliberately manipulating their languages so as to set themselves apart from their neighbours" (Thurgood \& Lapolla, 2003). This is just the tip of the linguistic iceberg!

Moving further east, to Arunachal Pradesh, the focus of the paper, the diversity is no less. Arunachal Pradesh is home to twenty five major tribes and about hundred sub-tribes. There is two (2) language ${ }^{3}$ and sixty (60) dialects ${ }^{4}$ spoken in the state. With the exception of two scripts, Boti and Thai, no other tribes have a written script. These two languages have been introduced in the primary classes in their respective area of domicile. The jurisdiction of Boti is confined to the primary schools in Mon areas of Tawang and West Kameng districts, inhabited by the believers (Mohanty, 2009) of Mahayana sect of Buddhism. Similarly, the Thai (Shaan) script, used in Thai Khampti language of Arunachal Pradesh is already in effect being taught to primary classes in Lohit district, inhabited by the Khampti tribe. Khamptis are followers of

\footnotetext{
${ }^{1}$ Multilingualism is the act of using, or promoting the use of, multiple languages, either by an individual speaker or by a community of speakers. (Wikipedia)

2 Multiculturalism refers to the doctrine that several different cultures (rather than one national culture) can coexist peacefully and equitably in a single country. (wordnetweb)

${ }^{3}$ Language here has been used to mean the one with a script.

${ }^{4}$ Dialect is for the ones without written script. But for the convenience of discussion, the word language will be used in the paper, even for the 'dialects'.
} 
Hinayana (Theravada) sect of Buddhism. Efforts are on to adapt and adopt the Roman script by many of the tribes. Like the language, the culture is also equally diverse and interesting.

Arunachal Pradesh was a terra-incognito until the WW II and India's Independence in 1947. 'During the British rule no serious attempt was made by the British Indian government to establish schools in the then North East Frontier Agency (NEFA), now Arunachal Pradesh. There only eleven schools in NEFA in the pre-independence period' ( Begi, 2007: 29). Schools in right earnest were started in the late 1940s only, with Assamese as medium of instruction in both pre-primary and primary Classes. It remained so until 1974, when it was switched to English in response to demands made by the then NEFA Students' Union. Since then English has been the medium of instruction at all levels of education with Hindi a second language and Assamese/Sanskrit as the third language in middle level (class VI-VIII).

\section{Linguistic Profile of Arunachal Pradesh}

Resource Centre for Indian languages Technology Solutions (RCILTS), IIT Guwahati classifies the languages of Arunachal Pradesh under the following categories:

- Tibeto-Burman

This group is further represented by various sub family namely, Tani, Hrusso, Lolo-Burmese, Monpa, Sherdukpen and Konyak. ${ }^{5}$

- Siamese-Chinese (sub family of Sino-Tibetan language family) is represented by Shaan and Khampti, the only two nonTibeto-Burman languages.

- Indo-Aryan: Asamiya/Axomiya. ${ }^{6}$

The two maps below will help in understanding the geographical distribution and the linguistic diversity of Arunachal Pradesh. ${ }^{7}$

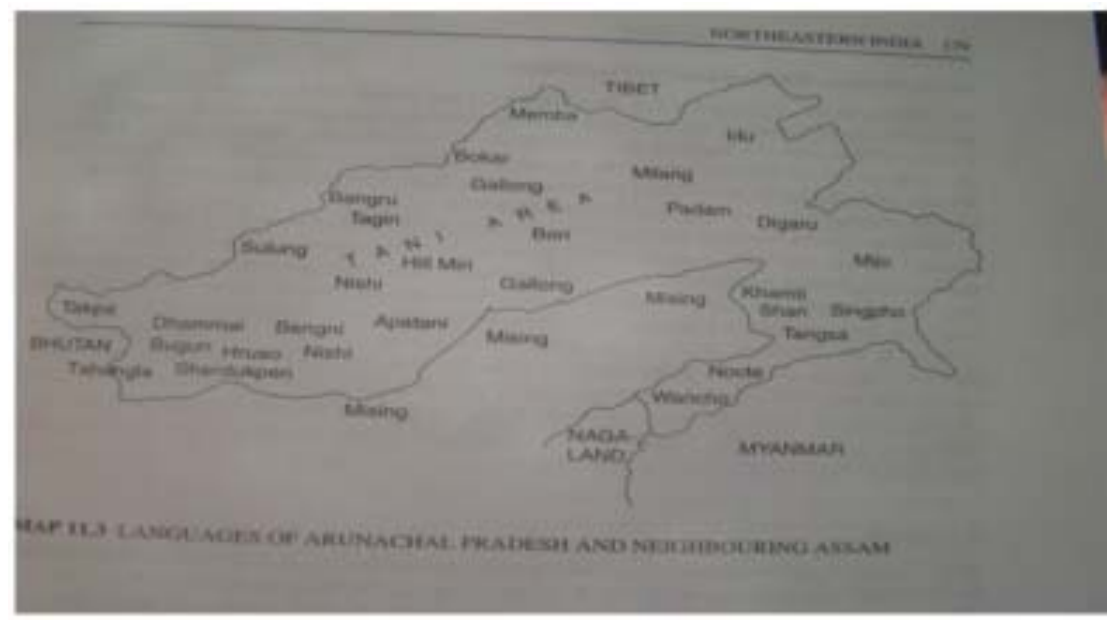

Fig.1.1: Linguistic map of Arunachal Pradesh. Source: Thurgood \& Lapolla 2003, P.179

\footnotetext{
5 In Arunachal Pradesh, the language spoken is known by the same name as that of its tribe. For example, Monpa, Hrusso, Sherdukpen, Nyishi and so on represent both the people (tribe) and the language spoken. But in the case of Konyak group, it is different. There is no tribe by the name of Konyak in Aruachal Pradesh. It is because 0 their linguistic and cultural affinity with the 'Konyak' tribe of neighboring Nagaland, that they have been called so.

${ }^{6}$ Assamiya/AxomiyalAssamese is a regional language of Assam not a mother tongue of any of the tribes in Arunachal Pradesh. The influence of Axomiya is high among the tribes bordering Assam and also for the fact that Assamese/Axomiya used to be the medium of instruction prior to 1974 and was still continued as third language in the middle level of school education in Arunachal Pradesh.

7 In this linguistic map of Arunachal Pradesh by Thurgood and Lapolla, Adi, one of the major tribes of Tani group having more than ninety thousand speakers is not reflected.
} 


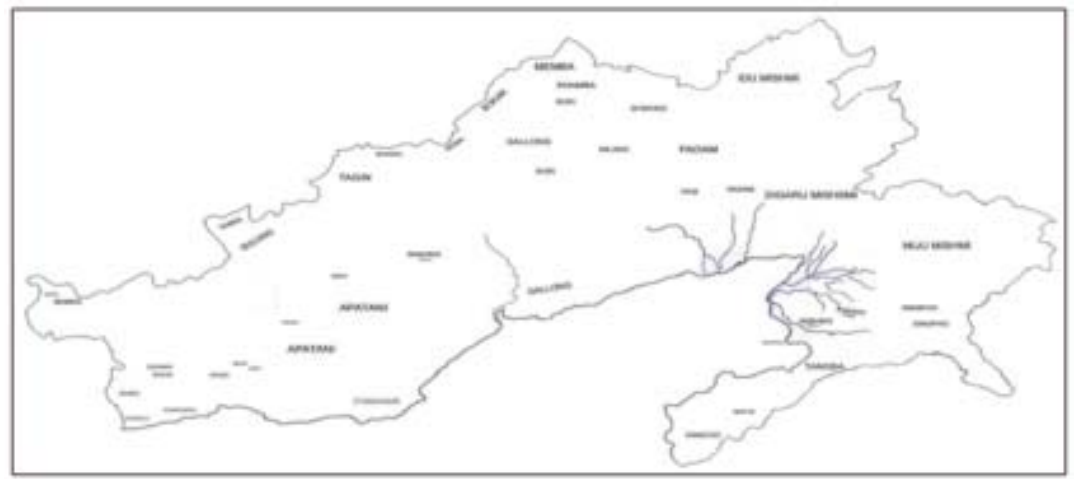

Fig. 1.2: Language map of Arunachal Pradesh. Source: RCILTS, IIT Guwahati. ${ }^{8}$

Similarly, culture of the people of may also be classified according to the linguistic groups. The Nocte and Wancho tribes are in the Konyak group are famed for their body tattoo art. The rites of passages, agricultural practices and food habits are also common between the two. The former by religion were originally Vaishnavites, a sect of Hinduism. The Wanchos however have been followers of indigenous faith. But many have been converted to Christianity in both the tribes in recent times. Mention may be made of the Tangsas, some of whose sub/tribes are Theravada Buddhists. Christianity has made inroads even among the Tangsas.

As the Tani group share same origin myths and legends, the culture is also quite akin among the tribes. Small differences can be found here and there which is but natural, given the vast geographical spaces that separate the groups. Face tattooing was popular among the Apatani tribe in the Tani group. The practice has been discouraged. It can be seen only in the older generation of the tribe. There are many festivals but one thing common about all the main festivals of the tribes are related to agricultural cycle.

Likewise, the tribes mentioned in the Monpa, Sherdupken and Hrusso have certain degree of cultural affinity among them. Whereas, Monpa, Sherdukpen, and some tribes in Hrusso group are Buddhists by religion, the Hrusso (people) themselves are not Buddhists. Even the Sulungs (Puroiks) are animist by faith.

Singpho is the only tribe in the Lolo-Burmese group. They may be different from the Khamptis linguistically but both the tribes follow the same religion and share similar cultural way of life too.

\section{Methodology}

The study is based on Primary as well as Secondary sources. For the primary source, students belonging to five major Tibeto-Burman speakers i.e. Tani, Hrusso, Monpa, Konyak and Shaan/Khampti were taken. The sample size was 250 comprising 50 (fifty) students each from these groups. The age group of the respondents ranged from 14 to 18 years. For the students pursuing Three years Bachelor of Arts/Bachelor of Commerce and Bachelor of Science, primary data has also been draw from the evaluation of their answer scripts in the House Tests (Internal examination) and Annual University examinations. The sample and the data are representative and not exhaustive.

\section{Analysis}

Resource Centre for Indian Languages Technology Solutions (RCILTS), Indian Institute of Technology Guwahati, India, has identified seven language groups in Arunachal Pradesh. Notwithstanding the lack of intelligibility among the different language groups, the Mutual Intelligibility (MI) factor even among intra-group is very less in some case. The diversity of language and culture and its impact can be understood from the hard fact that Arunachal Pradesh does not have an 'indigenous' language as a lingua franca. The tribes have not been able to come to unanimity regarding a 'local' lingua franca in the state. Besides the lack of organization and institution to facilitate in this matter, there is always the pull-push

${ }^{8}$ RCILTS in its district-wise Linguistic representation, has wrongly shown Apatani language as being spoken in two districts, Papum Pare and Lower Subansiri. Apatani, one of the major tribe in the Tani group is spoken in Lower Subansiri district only. The term Apatani represents both the language and the name of the tribe. See map 1.2 for reference. 
factor of 'majority' and 'minority' groups. An initiative by one Mr. Tony Koyu to develop indigenous script called 'Tani Lipi', a derivation of Devanagari script is yet to gain acceptability popularity because of the local community politics. The inventor of the script claims that it corresponds to all sounds in Tani group. The other language groups are still apprehensive. The efficacy of the script has not been evaluated as it has not been used formally. Moreover all the literate population is familiar with the Roman script and has voiced their support for adaptation of it to suit their specific languages. As has been mentioned in the introduction, there are only two languages having their own script i.e. Khampti/Shan with the Thai and Monpa with Boti script. As in the case of the Tani Lipi, these two scripts are not favored by other language groups as it is Greek to them. So Hindi and Assamese are the de-facto lingua franca among the different groups though English is the medium of instruction and the official language of the state.

Since structural language teaching should appropriately be corresponded by cultural knowledge, the effort to relate ELT to culture, to students unexposed to the foreign tongue and its accompanying intrinsic culture, can really prove to be a daunting exercise. The job of teaching and learning a foreign language may not prove very fruitful if the language teachers themselves were not adequately 'at home' with the target culture. Such seems to have been the case with English Language Teaching (ELT) in Arunachal Pradesh. In the initial years of Union Territory and later State building process, (13Au) (wordnet.web.Princeton.edu/perl/webwn)people from all parts of India were recruited as teachers to teach the illiterate mass. These teachers were mostly from northern India with strong Hindi background. Significant numbers were from neighboring Assam and from southern India too. Majority of them were from Vernacular media with little or no exposure to English culture while having the structural linguistic competence. The lacking of the teachers in target culture as well as native culture has led to many wrongly spelt native names and surnames. These teachers also carried with them their own personal cultural experiences and linguistic prejudices which they transmitted to their students unwittingly.

To cite an example, my own name got changed and surname remains inappropriately spelt as the teacher concerned, an Assamese, could not pronounce it correctly. My original name YELLI had to be changed to AZU my pet name. The teacher kept pronouncing it as ELLI, since he could not say 'YE', to which my sister who had taken me for admission objected. Similarly my surname TAW, should have been correctly written as TAO. Names of many places in Arunachal Pradesh are today incorrectly written and pronounced because the crusaders of education in the early years were unfamiliar with the local Pronunciation. And there were relatively few locals who could correct or guide them. To cite a few examples, Yazalyii became Yazali, Yochulyii to Yachuli, Aalo to Along, Cher to Sher, Lyichii to Lichi and so on.

The efficiency of learners was doubly incapacitated by their own native linguistic restrictions/shortcomings and unwitting transmission of inappropriate sounds by their teachers, tradesman and Government employees in the intial years of the State building process. Some of the typical vernacular sounds were 'chuha' (mouse) as 'suha', kacha (raw) as 'kasa' , V 'bhery' by our Assamese teachers; station as 'istation', school as 'ischool', blood as 'balad' by the north Indian teachers and yal, yum and yan for L,M,and $\mathrm{N}$ respectively by the southerners. This is not to say that all teachers were alike. There were exceptionally good teachers also. But as far as English pronunciation was concerned, it was heavily localized with few exceptions.

Examples are galore of natives' phonological faux pas as many of the tribal dialects do not have all the corresponding sound system of English, Hindi and many other languages. One can hear a Nyishi speaker (Tani) asking for 'kana' and 'hana' (Khana), rice in Hindi, ( khabar ,news 'kabar', thanda (cool) as 'tanda'. In Apatani tribe, where ' $h$ ', ' $r$ ' and ' $l$ ' is mildly pronounced, Naharlagun turns into 'Nuanagun' and Bus becomes 'Bans'. The sound ' $\mathrm{f}$ ' $v$ ' and 'ph' is absent in most tribes except in some sections of the Nyishi and Tangsa tribe where it is strongly accented. So, in case of the former, telephone becomes 'telipoon', office, 'oppice', fifty 'pipti', valley is 'balley', phase and face becomes 'pace'. In the latter office is 'ophice' and valley becomes 'phalley'. Raasta,( road), is 'daasta' among the Noctes (Konyak) of eastern Arunachal.

In many tribes despite the existence of particular sounds/phonemes, they use it inversely-one for the other. Hence among the Adis and Galos (Tani) one can be heard asking for 'siken' instead of 'chicken', achcha (good) is assa, narrating a 'chapna' instead of 'sapna'(dream), "Jalman kaan"for Salman Khan the bollywood actor and 'Jajan' for "sajan", name of a Salman Khanstarrer bollywood film. The Adis also use t and d inversely. So aadmi (man) becomes aatmi, matlab (meaning) becomes modlob and kitna (how much) is kedna.

Another interesting feature among the Nyishis (Tani) of East Kameng district is their literal translation of the mother tongue into English/Hindi. The sentence 'Na mingming hii hiye?' is supposed to mean 'what is your name?' but the word hiye in Nyishi actually means 'who' and not 'what'. So when it is translated into English or Hindi it goes like 'who' is your name? (English) and 'tumhara naam kaun hain ?' (Hindi).

Among the Monpas, 'down' is 'don', haddi (bone) is heddi and one is often offered jai (tea) instead of chai and so 
on. And a Khampti calls a 'bus' as 'baat' and 'rolling' as 'lolling' and 'low' as 'row'.

The linguistic impact on English education can be seen more from its respective mother tongues than from intergroup and intra-groups.

Hence many Hindi, Assamese and few English words have become part and parcel of many of the local languages.

\section{Hindi: The De-Facto Official Language}

The impact of mother tongues in English learning and other languages is quite visible. In addition to that, the popularity of Hindi and Assamese has not only impeded the learning of English but made quite an inroad into local tongues. The former by virtue of being the national language and the latter because of its status as medium of instruction up to 1973 in the state and also as third language too. The influence of Hindi is such that many of the second and third generation children do not speak their own mother tongue. It was a fashion in the 60s and 70s to teach Assamese to one's children rather than own mother tongue by the 'educated' people. It progressed to Hindi in the late 80s and 90s and the trend is still on.

Moreover, English teaching in primary classes were and still is practically done mostly in Hindi and Assamese. No doubt the lessons were read in English but explanations were/ are done either in Hindi or Assamese. Today, Hindi has taken over Assamese in almost all the regions. This explains the reason why students in Arunachal find it more comfortable to speak in Hindi than in English. Spoken English was not encouraged in any way. Exposure to spoken English was confined to the classroom alone. Majority being the first generation learners, there was no English to be heard, at home or among the peers.

The arrival of Televisions in homes also made little impact in terms of enhancing the spoken proficiency of the learners in the early years. Firstly, TV set was a luxury which every family could not afford not to talk of the absence of power supply, barring few urban/semi-urban areas only. Secondly, there were limited channels that too all in Hindi. Even after the onslaught of satellite channels in English, people prefer to watch Hindi programs. Moreover, the spoken English of Americans and Europeans are unfamiliar to our ears. The auditory mechanism of my generation and the one before, are attuned to the likes of 'Jha sir, Chutia sir and C.D. Rajen sir. Consequently dialogue in English movies becomes difficult to understand without the subtitles in the bottom. So is the case with English songs.

Given the diversity the state has in terms of language, culture and education legacy, the English language learning may be looked at with the emphasis on the social context. It has been clearly and firmly echoed by many experts in the field that language cannot be taught outside a social context. Learning of language is an individual act but it occurs in the society. The social context include components such as the sociolinguistic situation, the general exposure of learners to other languages, the roles of the target language and other languages in the outside community and in the home, and the general perception of values of the target language. "Whatever the language learners brings to the task, whether innate ability, a language acquisition device, attitudes, the outcome of language learning depends in large measure on the amount and kind of exposure to the target language" (Spolsky, 1989). It is this key element, "exposure to the target language" that is missing in the English education in the state owing to the various factors discussed above.

\section{Findings: Impact on English Education}

The impact of multilingualism on English education can be observed in phonological influence of mother tongues of the different speech communities, the verbatim transcription of it in English in spoken as well as written form. For example, with exception to Monpa group, in no tribe is 'sh' sound found. Hence the English words like 'shame, sheep, shambles are pronounced as 'same', sip, and sambles. The Nyishis (Tani group) of East Kameng district, use 'ing' in place of 'en/in/nd'. So 'chicken' becomes 'chicking', 'second' is 'secking' and 'join' is pronounced as 'joing'. The orthography is influenced by their pronunciation in many cases.

Influence of mother tongues can be heard all around in the state. It affects in speaker's fluency in other languages. In fact the local accents are so much tribe specific that one can easily identify the community of the speaker by his or her accent while speaking languages other than their own mother tongues. It can also be seen in hoardings and local advertisements.

In all the languages discussed here, none has gender specific pronouns like 'he' or 'she'. Besides the factors discussed above, lack of proper documentation and authentic research on most of the languages of Arunachal Pradesh, seem to be hampering the process of learning of other languages in the back drop of multilingualism and 
multiculturalism. Hence, in the absence of a point of reference, learning of other languages is affected.

The picture below is an example of mother tongue influence on orthography ${ }^{9}$

\section{Fig. 1.3}

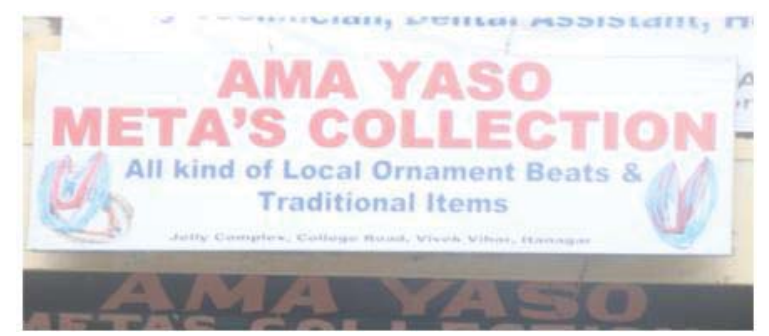

\section{Conclusion}

Multilingualism and multiculturalism is an integral part of a multi-ethnic State or a country. Migration, through the ages in the world has been taking place owing to various historical reasons. It has given rise to multilingual and multicultural societies. In the $21^{\text {st }}$ century, globalization has hastened the process even faster. It is a fact with which the concerned State or country has to live with and addressed to. In the case of Arunachal Pradesh, efforts may be initiated while planning language policy and curriculum to bridge the gap and minimize the degree of difference.

Initiatives may also be taken to develop the local languages/dialects, popularize it by introducing it in the school curriculum; train teachers in native and target grammar; develop academic material on the native languages; use electronic and social network media to minimize the inter-dialectical differences.

A humble endeavor has been made here to analyze various features and aspects of the impact of multilingualism and multiculturalism on English language learning with special reference to Arunachal Pradesh which is inhabited by the various tribes representing multilingualism and multiculturalism with their unique and rich heritage which still remains almost unexplored to most parts of the world. The researcher has painstakingly made all efforts to bring out and highlight the linguistic complexities arising out of inherent diversities in terms of both the languages and the cultures prevalent in this easternmost State of India.

\section{References}

(n.d.). Retrieved August 29, 2013, from en.wikipedia.org/wiki/multilingualism

Begi, J. (2007). Education in Arunachal Pradesh Since 1947 [Constraints, Opportunities, Initiatives and Needs]. New Delhi: Mittal Publications.

Census of India 2001, S. 1.-I. (2001). Language: India, States and Union Territories, Table C-16. New Delhi: Registrar General of India. Dev, A. (n.d.). Retrieved August 19, 2013, from Encylcopedia of life support system: www.eolss.net/sample-chapters/c04/E6-87-0705.pdf

Eds., S. K. (2009). Rethinking Multilingualism: Issues \& Problems. Guwahati: EPH Publishers (India).

Holliday, A. (1994). Appropriate Methodology and Social Context. Cambridge University Press.

Kramsch, C. (1993). Context and Culture in Language Teaching. Oxford University Press.

Lowes, G. (2007). Language and Cultural Preservation in Northeast India. Indigenousherald.com , 1-2.

Mohanty, K. Ajit\& Panda, Minati et.al (2009) (eds). Multilingual education for social Justice. Globalising the Local. Orient BlackSwan.

Resouce Centre for Indian Languages Technology Solutions, (Retrieved on 26th June 2013). Distribution of Languages in Arunachal Pradesh. Guwahati: RCILTS IIT guwahati.

Sharma, J. (2001, December). Multilingualism in India. Language in India Vol.1, pp. 1-6.

Spolsky, B. (1989). Conditions for Second language Learning. Oxford university Press.

Thurgood, G., \& Lapolla, R. J. (2003). The Sino-Tibetan Languages. London and New York: Routledge Taylor \& Francis Group. wordnet.web.Princeton.edu/per//webwn. (n.d.). Retrieved August 20, 2013, from en.wikipedia.org/wiki/multiculturalism

\footnotetext{
${ }^{9}$ The word "Beats" in the photo is supposed to mean "Beads".
} 